\title{
Potential Role of CHI3L1+ Astrocytes in Progression in MS
}

Laura Cubas-Núñez, PhD, * Sara Gil-Perotín, MD, PhD, * Jéssica Castillo-Villalba, BSc, Verónica López, BSc, Luis Solís Tarazona, MD, Raquel Gasqué-Rubio, BSc, Sara Carratalá-Boscá, MA,

Carmen Alcalá-Vicente, MD, PhD, Francisco Pérez-Miralles, MD, PhD, Hans Lassmann, MD, PhD, and

Bonaventura Casanova, MD, PhD

Neurol Neuroimmunol Neuroinflamm 2021;8:e972. doi:10.1212/NXI.0000000000000972
Correspondence

Dr. Gil-Perotín

sara.garcia@uv.es

\section{Abstract}

\section{Objective}

Neurofilament light protein (NfL) and chitinase 3-like 1 (CHI3L1) are biomarkers for acute neuroaxonal damage and local inflammation, respectively. Thus, we set out to evaluate how these biomarkers were associated with clinical features of demyelinating diseases in parallel with the expression in brain autopsies from patients with similar disease stages, assuming their comparability.

\section{Methods}

$\mathrm{NfL}$ and CHI3L1 in CSF and serum CHI3L1 were assessed retrospectively in a cross-sectional cohort of controls $(n=17)$ and patients diagnosed with MS $(n=224)$, relapsing $(n=163)$ or progressive $(n=61)$; neuromyelitis optica $(\mathrm{NMO}, \mathrm{n}=7)$; and acute disseminated encephalomyelitis (ADEM, $\mathrm{n}=15)$. Inflammatory activity was evaluated at the time of sampling, and CSF biomarker levels were related to the degree of inflammation in 22 brain autopsy tissues.

\section{Results}

During a clinical attack, the CSF NfL increased in MS, NMO, and ADEM, whereas CHI3L1 was only elevated in patients with NMO and ADEM and in outlier MS patients with extensive radiologic activity. Outside relapses, CHI3L1 levels only remained elevated in patients with progressive MS. CHI3L1 was detected in macrophages and astrocytes, predominantly in areas of active demyelination, and its expression by astrocytes in chronic lesions was independent of lymphocyte infiltrates and associated with active neurodegeneration.

\section{Conclusions}

Both CSF NfL and CHI3L1 augment during acute inflammation in demyelinating diseases. In MS, CHI3L1 may be associated with low-grade nonlymphocytic inflammation and active neurodegeneration and therefore linked to progressive disease.

\section{Classification of Evidence}

This study provides Class III evidence that CSF NfL and CHI3L1 levels increase in inflammatory brain diseases during acute inflammation.

*These authors contributed equally to this work.

From the Neuroimmunology Unit (L.C.-N., S.G.-P., J.C.-V., V.L., R.G., S.C., C.A., F.P.-M., B.C.), Polytechnic and University Hospital La Fe; Neurology Department (L.S.T.), University Hospital Dr Peset, Valencia, Spain; and Department of Neuroimmunology (H.L.), Center for Brain Research, Vienna, Austria. 


\section{Glossary}

ADEM = acute disseminated encephalomyelitis; AMS = acute MS; APP = amyloid precursor protein; $\mathbf{B B B}=$ blood-brain barrier; DMT = disease-modifying therapy; EDSS = Expanded Disability Status Scale; GFAP = glial fibrillary acidic protein; $\mathbf{I Q R}=$ interquartile range; $\mathbf{L P}$ = lumbar puncture; NAGM = normal-appearing gray matter; $\mathbf{N A W M}=$ normal-appearing white matter; NfL = neurofilament light protein; $\mathbf{N M O}=$ neuromyelitis optica; $\mathbf{P M S}=$ progressive $\mathrm{MS}$; $\mathbf{P P M S}$ = primary progressive MS; SEL = slowly expanding lesion; SPMS = secondary progressive MS; RRMS = relapsing-remitting MS.

MS is a pathology that can be considered a continuum, in which neuronal damage occurs in parallel to inflammation from the onset of the disease. ${ }^{1}$ This neuronal damage might be not perceived clinically due to compensation by functional neuronal reserves of the relatively young individuals affected. ${ }^{2}$ Thus, there is currently much interest in identifying biomarkers that will enable disease progression to be evaluated, even before a clinical diagnosis, and personalized treatment strategies to be adopted. We recently proposed that the combined assessment of 2 biomarkers in the CSF might identify patients with subclinical disease progression: neurofilament light protein (NfL) and chitinase 3-like 1 (CHI3L1). ${ }^{3}$ CHI3L1 is a member of the chitin family of proteins that are related to chronic inflammation. ${ }^{4}$ Within the brain, CHI3L1 is expressed by astrocytes ${ }^{5-7}$ and microglia/ macrophages, ${ }^{6-9}$ and its levels in the CSF reflect its endogenous synthesis. ${ }^{6}$ Indeed, elevations in CHI3L1 have prognostic implications in MS. ${ }^{3,10,11} \mathrm{NfL}$ is released into the CSF and serum on axonal damage, and in serum, it is considered a surrogate marker of disease activity in MS with potential prognostic value. ${ }^{12,13} \mathrm{NfL}$ and CHI3L1 levels also appear to be elevated during clinical attacks in other demyelinating diseases, such as neuromyelitis optica (NMO) ${ }^{14}$ and acute disseminated encephalomyelitis (ADEM) ${ }^{15}$ However, unlike MS, the accrual of neurologic disability independent of relapses is rare or absent in these entities. ${ }^{16,17}$

In the present study, we analyzed CHI3L1 and NfL levels in the CSF of patients with MS, ADEM, and NMO, and we compared these data with the expression of CHI3L1 and the degree of inflammation and neurodegeneration in autopsy tissue obtained from patients at similar disease stages. In terms of the clinical data, our primary end point was to assess the differences in the levels of these biomarkers between patients with distinct demyelinating diseases and in relation to their disease activity. From a pathologic viewpoint, the aim was to study the differential expression of CHI3L1 by distinct cell types and its relationship to the surrounding inflammation.

\section{Methods}

\section{Participants and Brain Samples}

Brain autopsy tissue was analyzed from 22 patients with MS and 6 age-matched controls $(\mathrm{n}=6)$ : acute MS (AMS)/ relapsing-remitting (RRMS: $\mathrm{n}=6$ ); primary progressive (PPMS: $\mathrm{n}=5$ ); secondary progressive (SPMS: $\mathrm{n}=11$ ), and 1 patient with $\mathrm{NMO}(\mathrm{AQP} 4+)$ and another 1 with ADEM (see patient characteristic and lesions analyzed in table 1). The clinical part of the study was performed on a cross-sectional cohort of 224 patients with MS (163 RRMS; 37 SPMS; 24 PPMS), 7 NMO (AQP4+), and 15 ADEM. Patients were attended at the Hospital Universitari i Politècnic La Fe between 2008 and 2017, and they were included in the study when CSF and serum samples, MRI, and longitudinal disability data were available. Demographic and clinical data were collected retrospectively and prospectively, with the last update in December 2019 (table 2). Non-MS control CSF samples $(n=17)$ were selected from patients with no evidence of infection, inflammation, autoimmunity, or known neurodegenerative disease.

\section{Standard Protocol Approvals, Registrations, and Patient Consents}

This clinical study was approved by the Institutional Ethics Committee in Hospital La Fe (reference number PI17/ 01544). The material for pathologic analysis was collected from the archive of the Center for Brain Research of the Medical University of Vienna (ethics committee number: 535/2004/2019).

\section{Data Availability}

The data sets analyzed in this current study are available from the corresponding author on reasonable request.

\section{Definitions}

Diagnosis of clinically definite MS was made prospectively according to the $2017 \mathrm{McDonald}$ criteria. ${ }^{18}$ An active disease was considered when a clinical attack occurred and/or at least 1 gadolinium-enhanced $(\mathrm{Gd}+)$ lesion was present in $\mathrm{T} 1$ weighted MRI. An increase in T2 lesions was not considered as activity because the temporal relationship with acute inflammation was not always well defined. A clinical attack or relapse was defined as acute worsening of neurologic activity lasting more than 24 hours, not explained by fever or physical stress, and followed by a varying degree of recovery. Urinary symptoms alone were not considered for a diagnosis of relapse. CSF samples were considered contemporary to active disease when a lumbar puncture (LP) was performed within 90 days of the assessment of clinical attack. Clinical phenotypes were classified according to the modified Lublin criteria. ${ }^{19}$ Patients were considered as SPMS when they had an Expanded Disability Status Scale (EDSS) score $\geq 3.0$ with a 6-month confirmed increase to an EDSS score of $\geq 4.0$, and in whom the pyramidal functional system was $\geq 2.0$ and there 
Table 1 Brain Specimen Characteristics

\begin{tabular}{|c|c|c|c|c|c|c|}
\hline Case & Type & Sex & Age & Lesion & Region of interest & Disease duration (mo) \\
\hline C1 & Control & $\mathrm{F}$ & 30 & & NWM & \\
\hline C2 & Control & $\mathrm{F}$ & 36 & & NWM & \\
\hline C3 & Control & $\mathrm{F}$ & 39 & & NWM & \\
\hline C4 & Control & M & 46 & & NWM & \\
\hline C5 & Control & M & 65 & & NWM & \\
\hline C6 & Control & M & 70 & & NWM & \\
\hline MS1 & AMS & M & 35 & Act. Lesion III & NAWM, initial, EA, and active center & 1.5 \\
\hline MS2 & AMS & $\mathrm{F}$ & 45 & Act. Lesion III, SEL & NAWM, initial, EA, LA, SEL: edge, and SEL: core & 0.2 \\
\hline MS3 & AMS & M & 45 & $2 \times$ Act. Lesion III & NAWM, initial, 2× EA, LA, and active center & 0.6 \\
\hline MS4 & AMS & M & 59 & Act. Lesion II & NAWM, EA, and active center & 5 \\
\hline MS5 & AMS & $\mathrm{F}$ & 69 & Act. Lesion III & NAWM, initial, EA, and LA & 2 \\
\hline MS6 & RRMS & $\mathrm{F}$ & 40 & Act. Lesion III & NAWM, initial, EA, and active center & 120 \\
\hline MS7 & PPMS & $\mathrm{F}$ & 34 & $2 \times$ inactive lesion & NAWM, $2 \times$ inactive core & 204 \\
\hline MS8 & PPMS & M & 53 & SEL & NAWM, SEL: edge, and SEL: core & 168 \\
\hline MS9 & PPMS & $\mathrm{F}$ & 55 & Active lesion I & NAWM, EA, and active center & 168 \\
\hline MS10 & PPMS & M & 67 & SEL & NAWM, SEL: edge, and SEL: core & 87 \\
\hline MS11 & PPMS & $\mathrm{F}$ & 77 & SEL & NAWM, SEL: edge, and SEL: core & 168 \\
\hline MS12 & SPMS & $\mathrm{F}$ & 52 & SEL and inactive & SEL and inactive & 30 \\
\hline MS13 & SPMS & M & 34 & SEL & NAWM, SEL: edge, and SEL: core & 120 \\
\hline MS14 & SPMS & M & 41 & SEL & NAWM, SEL: edge, and SEL: core & 137 \\
\hline MS15 & SPMS & $\mathrm{F}$ & 46 & SEL & NAWM, SEL: edge, and SEL: core & 444 \\
\hline MS16 & SPMS & $\mathrm{F}$ & 48 & Active lesion I & NAWM, EA, SEL, and inactive & 410 \\
\hline MS17 & SPMS & $\mathrm{F}$ & 53 & SEL & NAWM, SEL: edge, and SEL: core & 241 \\
\hline MS18 & SPMS & $\mathrm{F}$ & 53 & Inactive lesion & NAWM and inactive core & 360 \\
\hline MS19 & SPMS & $\mathrm{F}$ & 61 & Inactive lesion & NAWM and inactive core & 288 \\
\hline MS20 & SPMS & $\mathrm{F}$ & 62 & Inactive lesion & NAWM and inactive core & 144 \\
\hline MS21 & SPMS & $\mathrm{F}$ & 81 & Inactive lesion & NAWM and inactive core & 432 \\
\hline MS22 & SPMS & $\mathrm{F}$ & 45 & Active lesion & NAWM, EA, and SEL & 240 \\
\hline NMO & - & $\mathrm{F}$ & 20 & Active/inactive lesion & Active and inactive & 48 \\
\hline ADEM & - & M & 13 & Inf; act PV DM & NAWM; active lesions & 0.06 \\
\hline
\end{tabular}

Abbreviations: Act. = classical active lesions; $\mathrm{ADEM}=$ acute disseminated encephalomyelitis; $\mathrm{AMS}=$ acute MS; $\mathrm{EA}=$ early active lesion; $\mathrm{LA}=$ late active lesion; NAWM = normal-appearing white matter; NMO = neuromyelitis optica; NWM = normal white matter of controls; PPMS = primary progressive MS; RRMS = relapsing-remitting MS; SEL = slowly expanding lesion; SPMS = secondary progressive MS.

was no evidence of relapse. The PPMS phenotype was assigned to those patients who fulfilled the 2017 McDonald criteria for PPMS. Patients with MS were treated with a firstline disease-modifying therapies (DMTs) at the physician's discretion, unless one of the following circumstances occurred: (1) 2 clinical attacks in 1 year; (2) a clinical attack and/or a new Gd+ lesion within 3 months after a bout; and (3) a disabling clinical attack with residual EDSS of at least 2 points. In these cases and in those with treatment failure, a second-line DMT was administered. Nonresponders to firstand second-line DMT proceeded to autologous stem cell transplantation.

NMO was diagnosed according to the 2015 Wingerchuk criteria, ${ }^{20}$ and only seropositive patients for NMO-IgG were included in the study. ADEM was diagnosed according to the 
Table 2 Clinical and Demographic Characteristics of Patients

\begin{tabular}{|c|c|c|c|c|c|c|}
\hline Variable & Controls $(n=17)$ & RRMS $(n=163)$ & PMS (n = 61) & NMO $(n=7)$ & $\operatorname{ADEM}(n=11)$ & $\begin{array}{l}p \\
\text { Value }\end{array}$ \\
\hline Age at disease onset (y) & - & $30(24-37)$ & $35(25-43)$ & $42(31-48)$ & $38(20-52)$ & 0.405 \\
\hline Age at the time of LP $(y)$ & $35(31-36)$ & $34(28-41)$ & $46(40-53)$ & $42(35-50)$ & $43.50(22-54)$ & 0.273 \\
\hline Females & $9(53 \%)$ & $132(81 \%)$ & $28(47 \%)$ & $7(100 \%)$ & $3(23 \%)$ & 0.002 \\
\hline Time from diagnosis to LP (y) & - & $0.5(0.1-5)$ & $10.5(5.9-16.7)$ & $1(0-10)$ & $0(0-1)$ & $<0.001$ \\
\hline Follow-up from LP (y) & - & $3.7(1.8-5.4)$ & $3.5(2.1-5.8)$ & $6.6(4-9.9)$ & $2.2(0.7-4)$ & $<0.001$ \\
\hline Clinical relapse at the time of LP & - & $93(57 \%)$ & $3(5 \%)$ & $5(72 \%)$ & $7(62 \%)$ & 0.007 \\
\hline Gd+ in MRI at the time of LP & - & $77(48 \%)$ & $15(25 \%)$ & $2(29 \%)$ & $7(58 \%)$ & 0.524 \\
\hline OCB-IgG & $0(0 \%)$ & $142(88 \%)$ & $55(91.6 \%)$ & $2(29 \%)$ & $2(18 \%)$ & $<0.001$ \\
\hline OCB-IgM & $0(0 \%)$ & $81(50 \%)$ & $28(46.7 \%)$ & $2(29 \%)$ & $1(9 \%)$ & 0.007 \\
\hline Baseline EDSS score & 0 & $2(1-3)$ & $5(4-6)$ & $7(3-8)$ & $5(3-6)$ & $<0.001$ \\
\hline EDSS score $\geq 3.5$ & 0 & $32(19.6 \%)$ & $57(93.4 \%)$ & $5(71.4 \%)$ & $4(36.3 \%)$ & - \\
\hline $\begin{array}{l}\text { Treatment at LP (1st-line DMT, 2nd-line DMT, } \\
\text { and ASCT) }\end{array}$ & - & $30(20,9,1)$ & $25(8,17,0)$ & $4(3,1,0)$ & 0 & - \\
\hline NFL in CSF (pg/mL) & $\begin{array}{l}148.3 \\
(119.8-185.5)\end{array}$ & $\begin{array}{l}561.9 \\
(269-1,480)\end{array}$ & $\begin{array}{l}479.1 \\
(286-704.5)\end{array}$ & $\begin{array}{l}534 \\
(233-9,150)\end{array}$ & $\begin{array}{l}1,111 \\
(201-6865)\end{array}$ & 0.6 \\
\hline CHI3L1 in CSF (ng/mL) & $64.8(47.4-78.3)$ & $\begin{array}{l}115.6 \\
(80.5-186.1)\end{array}$ & $\begin{array}{l}159.93 \\
(104-229.5)\end{array}$ & $\begin{array}{l}208.2 \\
(111-448)\end{array}$ & $\begin{array}{l}374.2 \\
(109-634)\end{array}$ & 0.01 \\
\hline
\end{tabular}

Abbreviations: $\mathrm{ADEM}=$ acute disseminated encephalomyelitis; $\mathrm{ASCT}=$ autologous stem cell transplantation; $\mathrm{CHI}$ 3L1 = chitinase 3-like 1; DMT = diseasemodifying therapy; EDSS = Expanded Disability Status Scale; Gd+ = gadolinium-enhancing lesion; LP = lumbar puncture; NfL = neurofilament light chain; NMO = neuromyelitis optica; OCB = oligoclonal band; PMS = progressive MS; RRMS = relapsing-remitting MS.

Categorical variables are described as counts ( $n$ ) and percentages (\%) and continuous and ordinal variables by median (first and third quartiles).

2012 IPMSSG criteria. ${ }^{21}$ In all cases, disability was estimated according to the EDSS $^{22}$ at the time of LP and every 6 months until the last visit. AMS for pathologic studies was diagnosed in the case of rapidly progressive and malignant forms of MS that led to death within weeks to months from onset, without any signs of remission. ${ }^{23}$ Most patients died due to cardiac or respiratory complications.

\section{Biomarker Measurement}

CSF and serum samples were stored at $-80^{\circ} \mathrm{C}$ in the Biobank at the La Fe hospital and with the approval of the Ethics and Scientific Committees (PT17/0015/0043). CHI3L1 and NfL CSF levels were assessed as reported previously following consensus guidelines for CSF collection and biobanking. ${ }^{24}$ The mean intraassay coefficients of variation for NFL and CHI3L1 were $4.5 \%$ and $6.5 \%$, respectively, and the interassay coefficients were $3.3 \%$ and $5.2 \%$, respectively. We considered patients with biomarker levels more than 1.5 times the interquartile range (IQR) above the $\mathrm{Q} 3(\mathrm{CHI} 3 \mathrm{~L} 1>367 \mathrm{ng} / \mathrm{mL}$; $\mathrm{NfL}>2027 \mathrm{pg} / \mathrm{mL}$ ) calculated in the global MS cohort as outliers. Serum CHI3L1 levels (sCHI3L1) were measured at a 1:50 dilution in 88 CSF samples using the same kit (DC3L10, $\mathrm{R} \& \mathrm{D}$ systems, Minneapolis, MN). To assess blood-brain barrier (BBB) permeability, the albumin index ( $\mathrm{Q}-\mathrm{alb})$ was calculated for all the samples as the ratio of CSF $(\mathrm{mg} / \mathrm{L})$ to the serum albumin concentration $(\mathrm{g} / \mathrm{L})$.

\section{MRI Acquisition and Analysis}

Brain, cervical, and dorsal spine MRI after a first clinical attack were analyzed. As the initial studies were from different centers and over a long time period (2006-2019), the acquisition protocol and the sequences used were variable. Nevertheless, the FLAIR sequence (transverse or sagittal planes with a thickness between 1 and $3 \mathrm{~mm}$ ), turbo spin echo T2 sequence (3-5 mm thick), proton density sequence (3-5 mm thick), and $\mathrm{T} 1$ sequence after administration of gadolinium (transverse plane and 3-5 mm thick) were available in all cases for analysis. Lesions were classified according to their location, number, and postgadolinium enhancement.

\section{Immunohistochemistry}

Histochemistry and immunohistochemistry were performed on sections to distinguish: normal-appearing white matter (NAWM) at least $1 \mathrm{~cm}$ from any lesion; classical active lesions following the type I, II, or III pattern of demyelination ${ }^{25}$; slowly expanding lesions (SELs); and inactive lesions. All these lesions were defined according to previously published criteria. ${ }^{26-28}$ Immunohistochemistry was performed using the biotin-streptavidin method, the details of which were provided previously. ${ }^{29}$ Sections were incubated with a CHI3L1 antibody (AF2599, R \& D Systems) diluted in Dako buffer (S3006, Dako, Agilent, Santa Clara, CA), with $10 \%$ horse serum to block nonspecific protein binding, whereas the rest of the antibodies were diluted in Dako buffer 
containing $10 \%$ fetal calf serum. For triple immunofluorescence, Dako diluent (Dako S3022) was used as the blocking buffer and to dilute the primary antibodies. Secondary antibodies were added sequentially. Images were acquired with an optical microscope Nikon Eclipse Ci (Nikon, Tokyo, Japan) and for immunofluorescence with a confocal microscope Olympus FV1000 (Olympus, Tokyo, Japan). The features of the antibodies used and the staining conditions (e.g., concentration, antigen retrieval) are summarized in tables e-1, links.lww.com/NXI/A427 and e-2, links.lww.com/NXI/A428, and for further details about CHI3L1 assessment, see Appendix e-1, links.lww.com/NXI/A422. As controls, immunohistochemistry was performed in the absence of the primary antibody. Images were obtained with a confocal (Olympus FV1000) and optical microscope (Nikon Eclipse Ci).

\section{Statistical Analysis}

Statistical analysis was performed with IBM SPSS v 26.0 software. Regarding clinical data, our primary end point was to assess differences in the levels of biomarkers between patients with distinct demyelinating diseases to relate those to disease activity. From a pathologic viewpoint, the aim was to study the differential expression of CHI3L1 by distinct cell types and its relationship to the inflammatory milieu. The descriptive analysis included the median value and IQR. Differences between the groups in the histologic studies were assessed with a Mann-Whitney $U$ test due to the non-normal distribution of the data. For clinical studies, the logarithmic NfL and CHI3L1 values were used and parametric tests were run using an analysis of covariance, adjusting for baseline covariates. In the case of multiple testing (comparisons between more than 2 groups), significant values were corrected with the Bonferroni-Holm procedure. Reported $p$ values were the result of 2 -sided tests, and a $p$ value $<0.05$ was considered statistically significant. There were no missing values among the variables analyzed because the inclusion criteria required all values to be collected for a patient to be selected.

\section{Results}

\section{$\mathrm{NfL}$ and CHI3L1 Are Elevated in the CSF of Patients With MS, With Distinct Concentrations Associated With Different Lesion Stages}

When measured in the CSF of patients with MS, the median values of $\mathrm{CHI} 3 \mathrm{~L} 1\left(\mathrm{CHI} 3 \mathrm{~L}^{\mathrm{CSF}}\right)$ and $\mathrm{NfL}\left(\mathrm{NfL}^{\mathrm{CSF}}\right)$ were higher than in the controls $(p<0.001$ : table 2$)$, although there were differences among the MS patients in terms of the expression and release of these markers (figure 1). An elevation in $\mathrm{NfL}^{\mathrm{CSF}}$ levels was mainly evident in patients with MS with disease activity $(p<$ 0.001: figure $1 \mathrm{~A}$ ), and it was higher in the RRMS subgroup compared with patients with progressive MS (PMS) $(p=0.003)$. These differences were irrespective of sex, disease duration, or age at the time of LP. Elevated $\mathrm{NfL}^{\mathrm{CSF}}$ levels were also associated with the incidence (figure $1 \mathrm{E}, p<0.001$ ) and number of $\mathrm{Gd}+$ lesions in MRI $(p<0.001 ; r=0.495$ : supplementary figure $1 \mathrm{~A}$, links.lww.com/NXI/A423).

In contrast to $\mathrm{NfL}, \mathrm{CHI} 3 \mathrm{~L}_{1}{ }^{\mathrm{CSF}}$ levels were higher in patients with PMS than in patients with RRMS $(p=0.009)$ after adjusting for sex, disease duration, or age (table 1). The EDSS at the time of LP was mildly correlated with the $\mathrm{NfL}^{\mathrm{CSF}}$ and CHI3L1 ${ }^{\text {CSF }}$ values $(r=0.190 ; p=0.03 ; r=0.308 ; p<0.001$, respectively). However, no correlations were evident between the $\mathrm{NfL}^{\mathrm{CSF}}$ or CHI3L1 ${ }^{\mathrm{CSF}}$ values and overall lesion load ( $p=$ 0.349 and $p=0.331$, respectively) or the location of inactive T2 lesions, and these values only increased moderately with radiologic activity (figure $1 \mathrm{E}$ and supplementary figure $1 \mathrm{~B}$, links.lww.com/NXI/A423). There was no difference in the CHI3L1 ${ }^{\mathrm{CSF}}$ levels between patients with or without disease activity ( $p=0.969$; figure $1, \mathrm{~B}$ and C), although CHI3L1 outliers (more than 1.5 times the IQR above the Q3) corresponded to patients with a confirmed clinical attack, elevated $\mathrm{NfL}^{\mathrm{CSF}}$, and widespread Gd-enhanced lesions concentrated in periventricular and juxtacortical locations (figure $1 \mathrm{~F}$ ).

\section{Pathologic Correlations in Part Explain the Differences Between NfL ${ }^{\mathrm{CSF}}$ and CHI3L1 ${ }^{\mathrm{CSF}}$ in MS Clinical Phenotypes}

Global expression of CHI3L1 in MS lesions was determined through the optical density that measured antibody binding in sections, which followed the patterns of CHI3L1 release into the CSF described above. In MS brains, there was stronger $\mathrm{CHI} 3 \mathrm{~L} 1$ expression than in the control's white matter (figure 2, A-C) and cortex (figure 2, $\mathrm{D}-\mathrm{F}$ ), and although CHI3L1 expression was most pronounced in early active lesions, it was also very prominent in PMS (figure 3; table e-3, links.lww.com/NXI/A429). Indeed, the strongest expression was seen at active lesions and in the NAWM of patients with AMS (figures 2, B, G-I and $3 \mathrm{~A}$ ). Strong expression was also evident in the chronic active lesions and SEL of PMS tissue (figures 3A and 4J-L). A more detailed analysis showed that CHI3L1 was mainly expressed by 2 cell types, microglia/macrophages and astrocytes (supplementary figure 2A-C, links.lww.com/ $\mathrm{NXI} / \mathrm{A} 424)$. The expression of CHI3L1 in $\mathrm{CD}_{6} 8^{+}$ macrophages/microglia was mainly seen at early stages of disease activity (figure $2 \mathrm{H}-\mathrm{I}$ ). The $\mathrm{CHI} 3 \mathrm{~L} 1+/ \mathrm{Iba} 1+$ cells were round, whereas only rarely was CHI3L1 detected in Iba1+ cells with a ramified morphology. At later stages of disease activity (chronic active lesions), CHI3L1 expression by astrocytes in SEL and in the NAWM or normalappearing gray matter (NAGM) predominated (figures 2B-C, E-F and 4J-L). Although its expression was diffuse in the NAWM or NAGM, in late active and chronic lesions, including SEL, CHI3L1+ astrocytes were found at the periphery of the lesions forming an active border (see arrows in figures $2 \mathrm{I}$ and $4 \mathrm{~J}-\mathrm{L}$ ). Only very weak expression was seen in inactive lesions (supplementary figure 3A-F, links.lww. com/NXI/A425).

Regarding the association of CHI3L1-expressing cells (figure 3B-E) with inflammatory infiltrates in late active lesions, the number of these cells correlated with the density of $\mathrm{CD} 68^{+}$macrophages/microglia $(r=0.626$; $p<$ 0.001 ) (figure $3 \mathrm{D})$. Although there was some correlation 
A

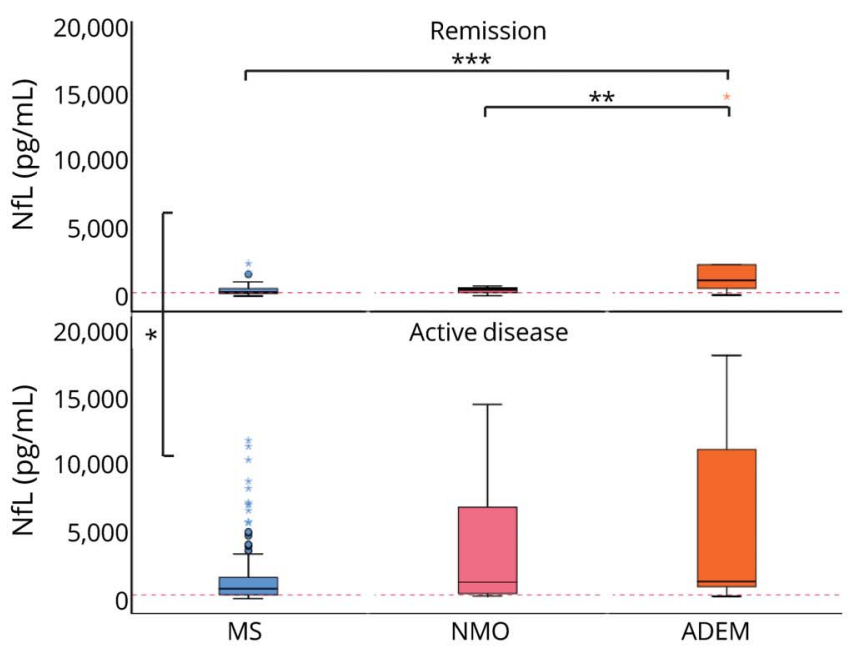

C
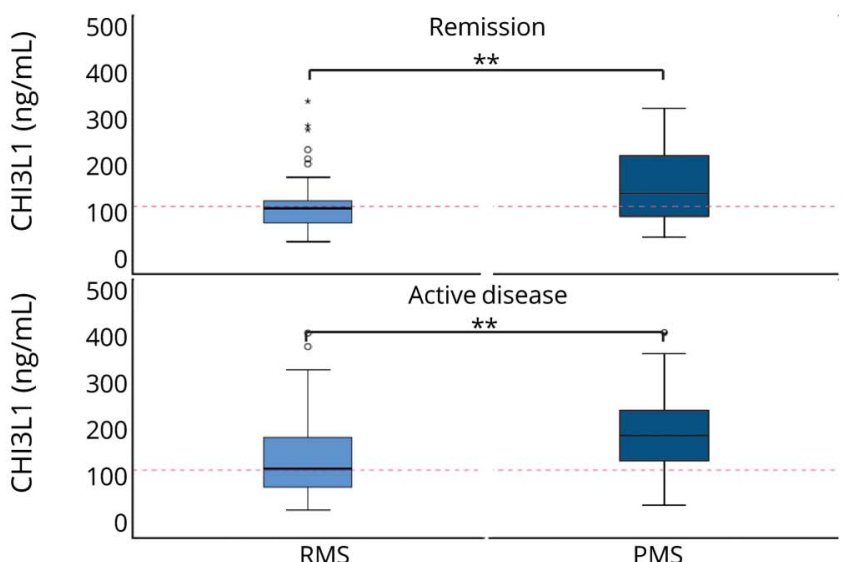

E

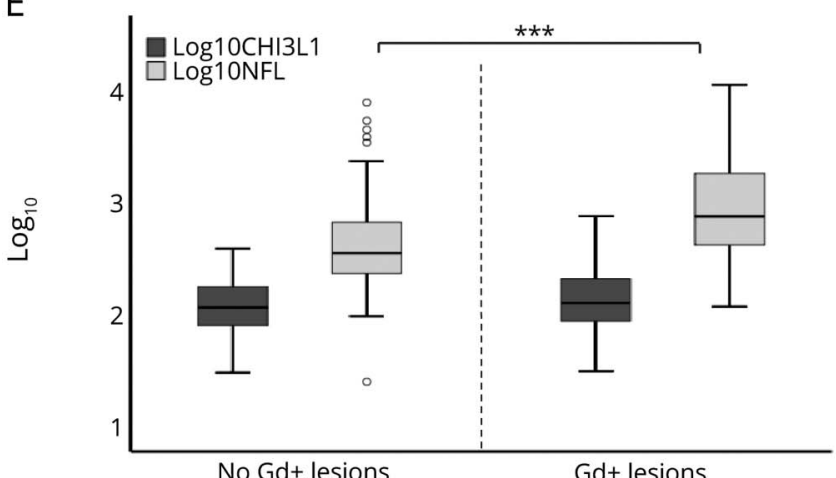

B

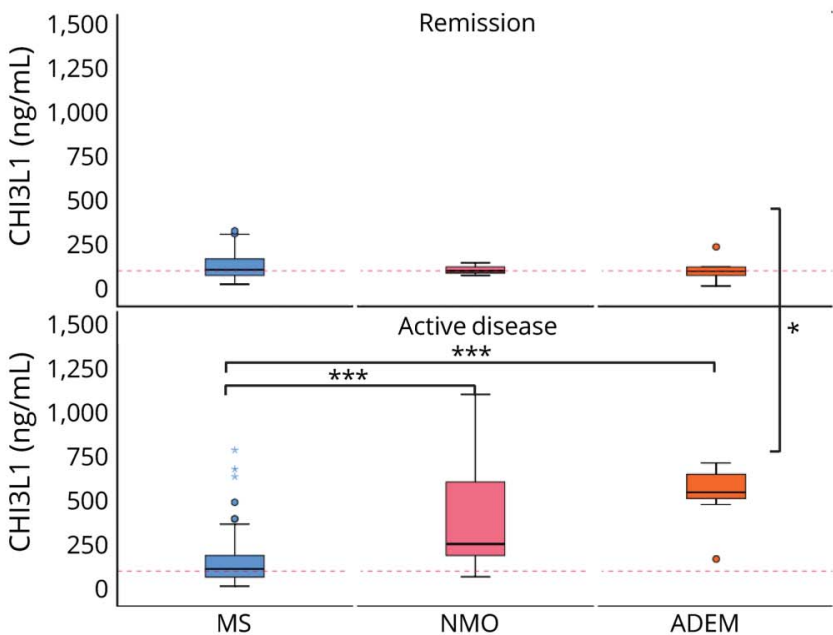

D

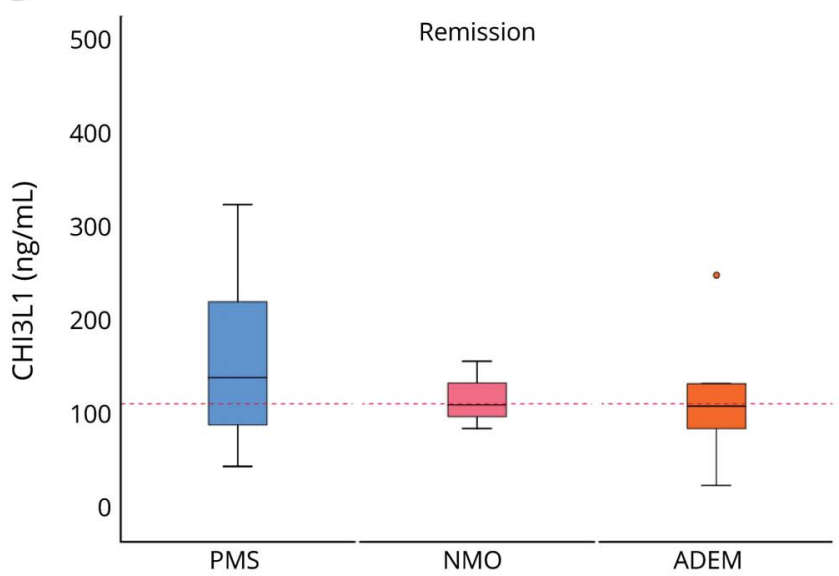

F

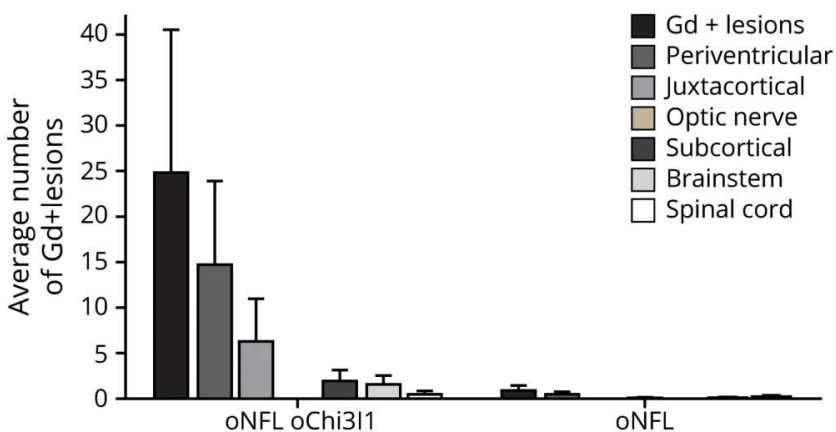

(A) NfL levels in the CSF increased significantly in patients with MS in the context of disease activity alone. In remission, the levels of NfL in the patients with ADEM differed significantly to those in the patients with MS and NMO. (B) Increased CHI3L1 levels in the CSF of patients with MS, NMO, and ADEM during disease activity, and they were higher in the NMO and ADEM samples than in those from patients with MS. The levels of CSF CHI3L1 in ADEM were significantly higher than in the remission phase. (C) There was significantly more CHI3L1 in progressive MS (PMS) irrespective of disease activity. (D) There was a trend toward more CHI3L1 in patients with PMS than in patients with NMO and ADEM in remission. (E) NfL levels in the CSF were associated with radiologic activity, with a trend toward an association with CHI3L1. (F) The average number of Gd+ lesions in MS and the distribution of these lesions in patients with high levels of NfL and CHI3L1 (oNfL/ OCHI3I1) or high NfL and low CHI3L1 (oNfL). Median levels of NfL and CHI3L1 in RMS outside relapse are represented as a red line for reference. A $p$ value of $<0.05$ was considered statistically significant $\left({ }^{*} p<0.05 ;{ }^{*} p<0.01 ;{ }^{* *} p<0.001\right)$. ADEM = acute disseminated encephalomyelitis; CHI3L1 = chitinase 3-like 1 ; Gd+ = gadolinium-enhanced lesion; NfL = neurofilament light protein; NMO = neuromyelitis optica; oCHI3L1 = outlier CHI3L1; oNfL = outlier NfL; RMS = relapsing MS.

between the density of $\mathrm{CD}^{+} 8^{+}$cells and lymphocyte infiltration into the tissue (figure $3 \mathrm{E}$ ), no association was found between $\mathrm{CD}^{+} 8^{+}$cells and meningeal follicles $(p=$
$0.621)$ or between the CHI3L1+ cells and lymphocytic aggregates in the NAWM $(p=0.116)$ or meninges $(p=$ $0.627)$. 

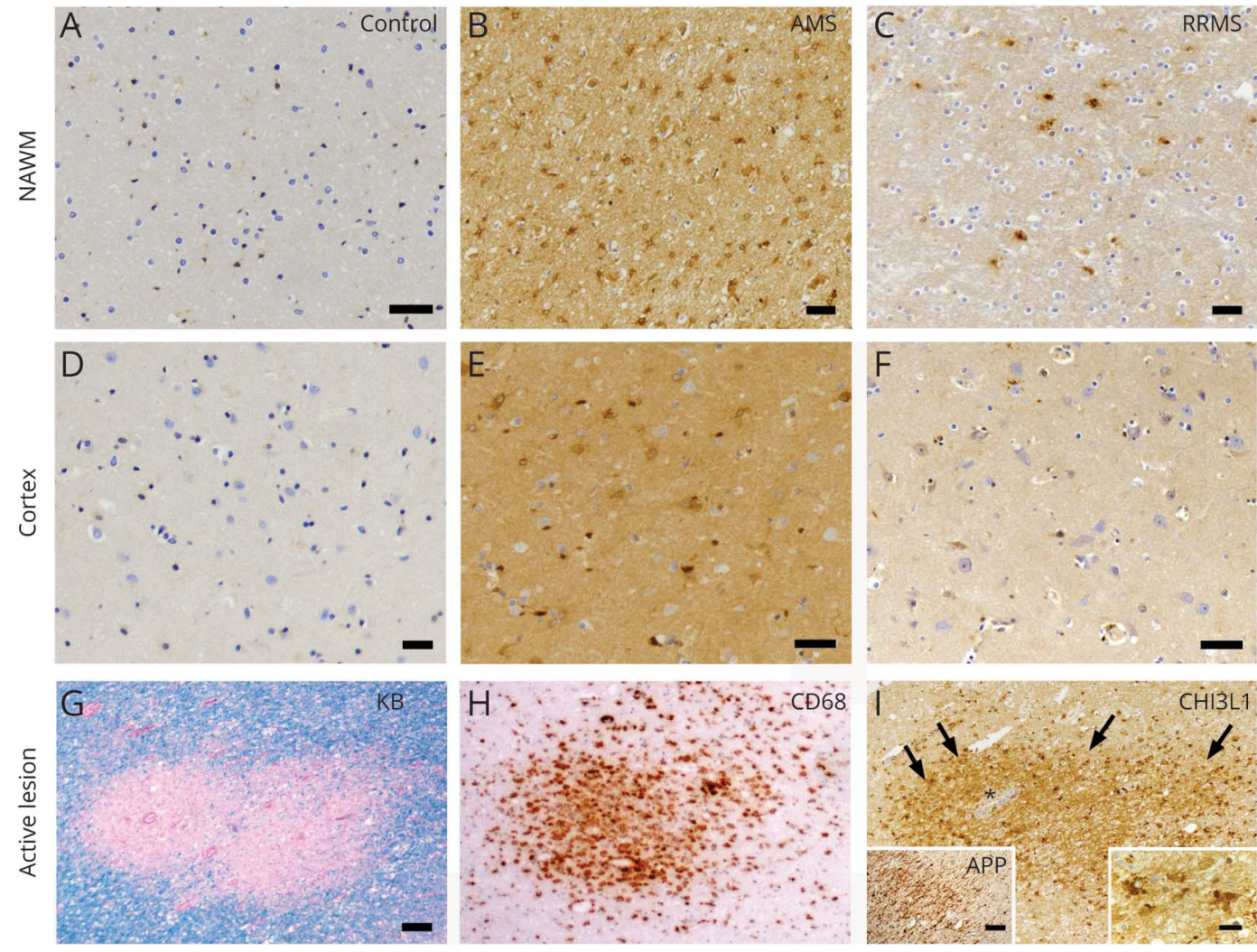

Light microscope micrographs of AMS and RRMS specimens (A-I). NAWM (A-C). CHI3L1 expression was not found in the NAWM of controls (A), whereas diffuse expression was detected in patients with AMS (B) and RRMS (C). Cortex (D-F). Similarly, no CHI3L1 expression was detected in control specimens (D), whereas it was weakly expressed in the cortex of patients with AMS (E) but not patients with RRMS (F). Active lesion (G-I). A typical early active white matter lesion in a patient with AMS with profuse perivenular infiltrates of $\mathrm{CD} 68^{+}$cells $(\mathrm{H})$ and demyelination, as shown by Klüver-Barrera staining (G). CHI3L1 expression (I) was intense within the lesion, expressed in the center by round cells that correspond to microglia, and at the periphery or active border by larger ramified cells corresponding to astrocytes (arrows in I). CHI3L1, chitinase 3-like 1; AMS = acute MS; NAWM = normal-appearing white matter; RRMS, relapsing-remitting MS.

The pathologic correlates of NfL in the CSF were acute neuronal and axonal damage. The best pathologic indicator was axonal dystrophy, reflected by the accumulation of amyloid precursor protein (APP) in dystrophic axons and neurons, due to a disturbance of acute axonal transport. A considerable number of APP+ spheroids were found in active lesions (figure 2I left detail), and they were spatially related to the CHI3L1 expressed by astrocytes, yet not by microglia, at the edge of the active and chronic active lesions or SELs (figure 4G-I; detail in fig $4 \mathrm{H}$; supplementary figure 4, links.lww.com/NXI/A426).

\section{CHI3L1 Is Not Expressed Outside of Relapses in Monophasic or Relapsing Inflammatory Demyelinating Diseases That Lack a Progressive Stage}

In addition to the very high NfL levels (figure 1A), the most characteristic change in the CSF of AQP4+-NMO patients during a clinical attack was the extreme increase in CHI3L1, which was two-fold higher than in MS and that remained significantly different after adjusting for sex, age, and disease duration $(p<0.001$; figure $1 \mathrm{~B})$. $\mathrm{CHI} 3 \mathrm{L1}{ }^{\mathrm{CSF}}$ levels did not correlate with the number of contrast-enhancing lesions $(r=0.632 ; p=$
0.253 ), and these values normalized in remission when they were lower than in PMS. However, the small sample size precluded assessing the statistical significance of these changes (figure 1D).

In the brain specimen of NMO analyzed, 2 active lesions and an inactive lesion were identified, with AQP4 staining showing the lesion center to be devoid of astrocytes (figure 5A-B). The active center was infiltrated by $\mathrm{CHI} 3 \mathrm{~L} 1+/ \mathrm{CD} 68+$ cells and characterized by a ribbon of hypertrophic astrocytes at the border of the lesion, cells that coexpressed CHI3L1 and glial fibrillary acidic protein (GFAP) strongly (figure $5 \mathrm{C}-\mathrm{E}$ ). CHI3L1+ astrocytes were enlarged and had lost their expansions, a process known as clasmatodendrosis (figure 5E, inset), normally followed by necrosis. $\mathrm{CHI} 3 \mathrm{~L} 1+$ astrocytes were absent from the inactive center, NAWM, and NAGM. However, CHI3L1 immunoreactivity persisted in the extracellular space of some inactive lesions (figure $5 \mathrm{H}$ ), which could be explained by massive release from necrotic astrocytes into the extracellular space.

ADEM is a short-lasting inflammatory disease in which a monophasic attack is followed by the clearance of inflammation, 


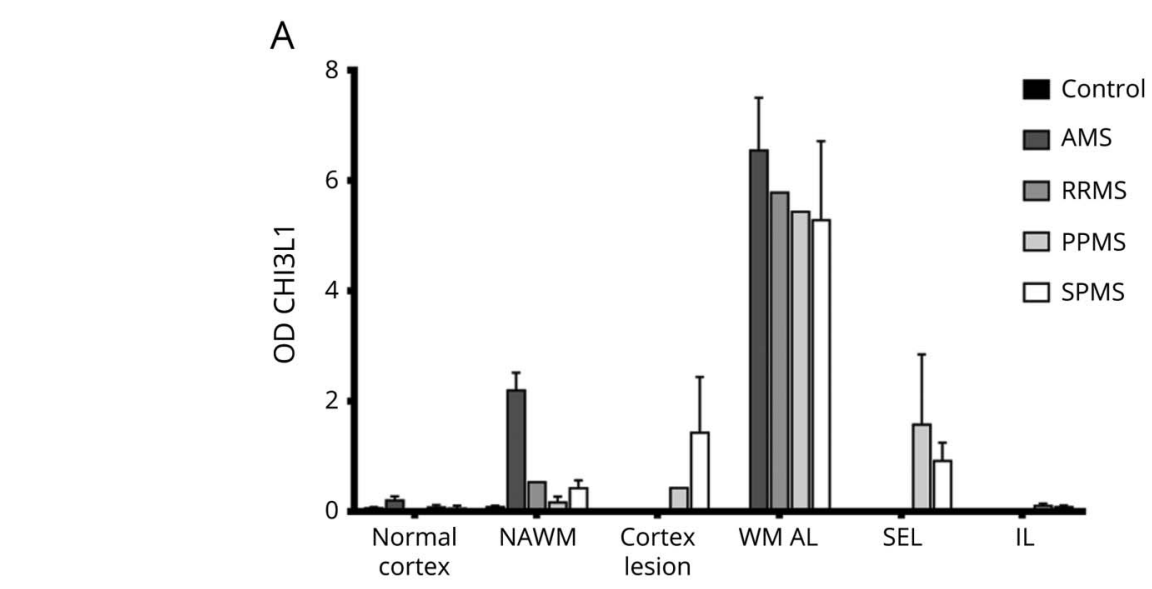

B

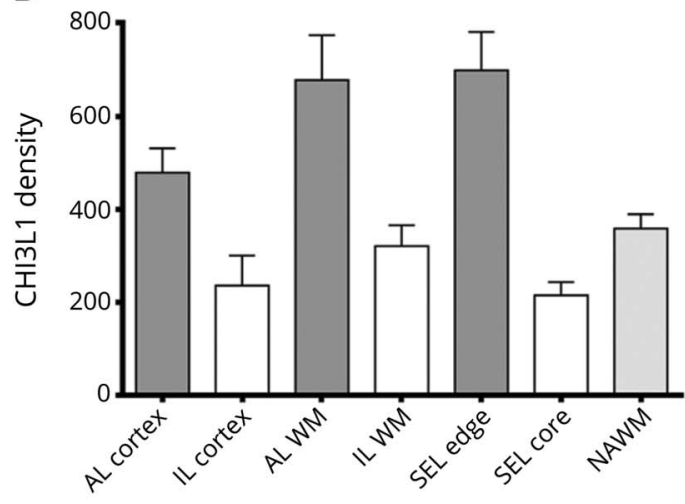

$\mathrm{D}$

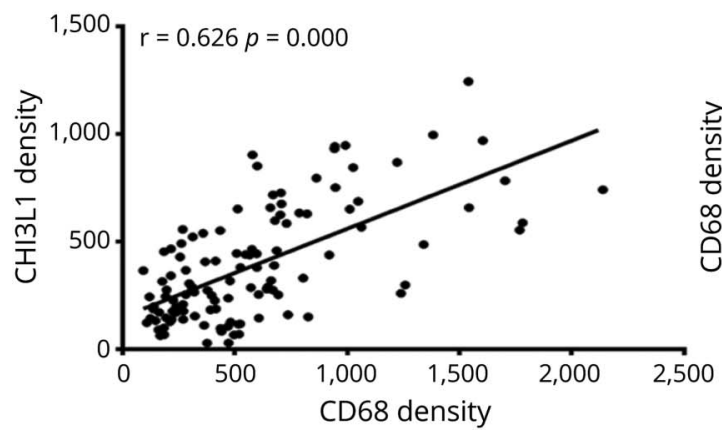

C

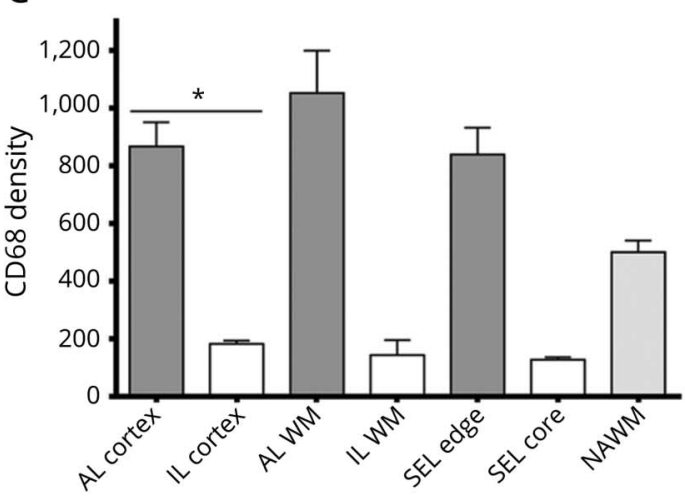

$\mathrm{E}$

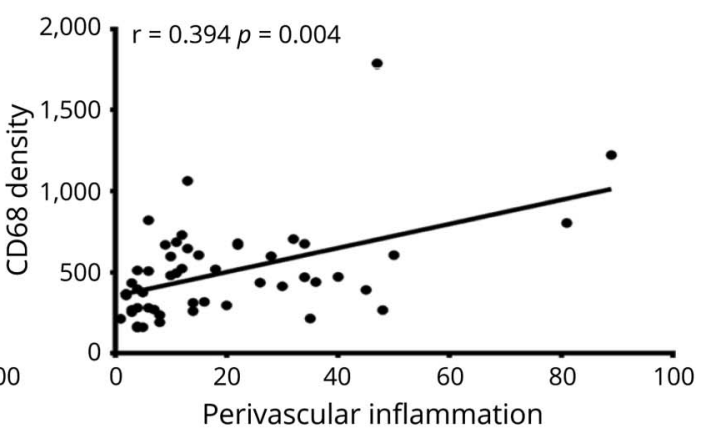

(A) Quantification of CHI3L1 expression, measured by the OD of staining in different areas of all MS and control specimens. (B) Density of CHI3L1+ cells in each area and type of lesion. (C) Density of CD68 ${ }^{+}$cells in the distinct types of lesions. (D) There was a positive correlation between CHI3L1 and CD68 expressing cells in all the regions analyzed. (E) There was a positive correlation between perivascular infiltrates and CD68 ${ }^{+}$cells but not with CHI3L1-expressing cells (not shown). CHI3L1 density: AL cortex vs IL cortex $(p=0.053)$, AL WM vs IL WM $(p=0.083)$, and SEL edge vs SEL core $(p=0.053)$. *CD68 density: AL cortex vs IL cortex $(p=0.000)$, AL WM vs IL WM $(p=0.083)$, and SEL edge vs SEL core $(p=0.053)$. AL = active lesion; AMS = acute MS; CHI3L1 = chitinase 3-like 1; IL = inactive lesion; $\mathrm{OD}=$ optical density; PMS = progressive MS. SEL = slow-expanding lesion; $\mathrm{WM}=$ white matter.

some perivascular axonal loss, astrocyte gliosis, and remyelination of the remaining demyelinated axons. Extremely high NfL values were registered in the CSF (figure 1A), reflecting the extensive and acute axonal damage that was associated with a worse EDSS $(r=0.622 ; p=0.031)$. Likewise, CSF CHI3L1 reflected the intense inflammatory activity in the early stages of disease (figure $1 \mathrm{~B}$ ) and its later normalization compared with PMS (figure 1D), which was correlated with the time from the clinical attack $(r=-0.649 ; p=0.012)$. The early liberation of
CHI3L1 into the CSF was apparently due to perivascular activated microglial infiltration into the active lesions, NAWM, or NAGM (figure 5I-J), as no CHI3L1-expressing astrocytes were found in the ADEM case analyzed.

\section{Serum CHI3L1 Levels Are High in PPMS but They Do Not Reliably Reflect CHI3L1 ${ }^{\text {CSF }}$ Levels}

As $\mathrm{CHI} 3 \mathrm{~L} 1^{\mathrm{CSF}}$ levels might be informative of innate inflammatory disease activity in patients with RRMS or PMS, we 

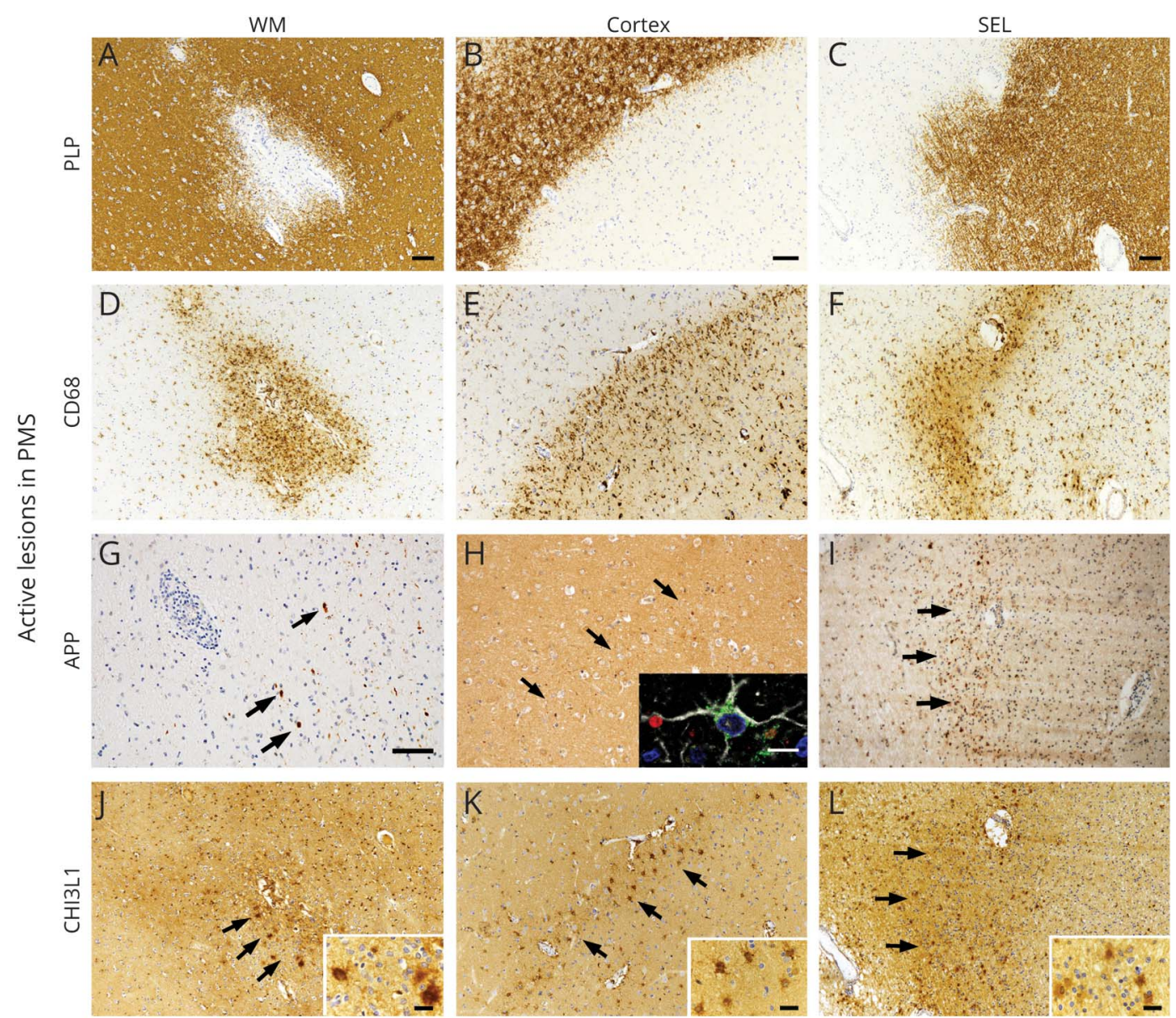

PLP
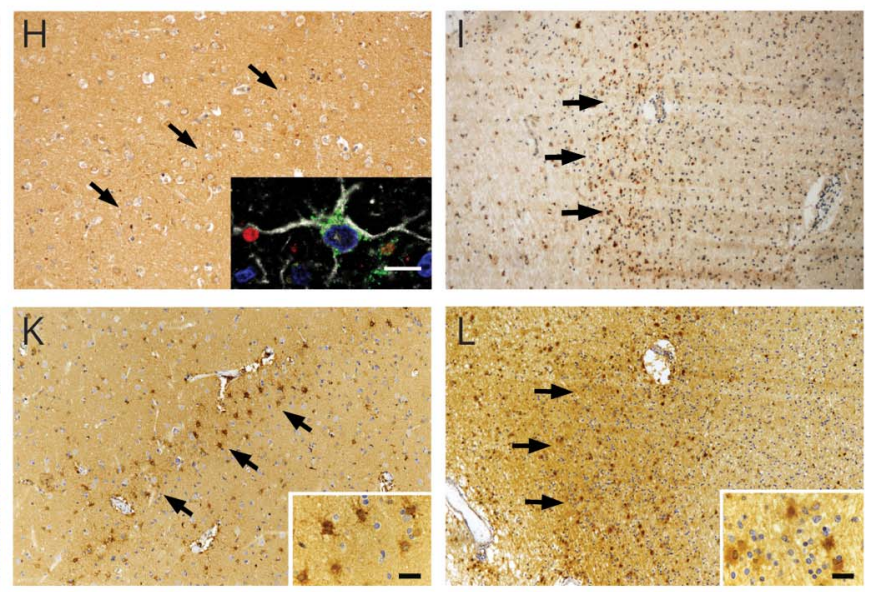

CD68

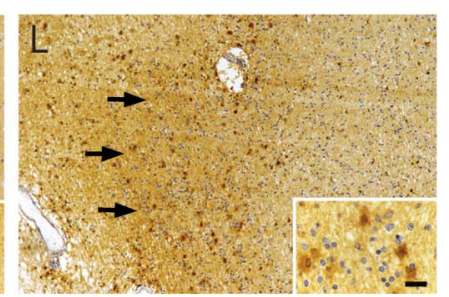

CHI3L1

Light microscopy micrographs of active and inactive lesions in patients with PMS. Active lesions in the WM (left column), cortex (medium column), and SEL (right column) (A-L). All active lesions displayed extensive demyelination, evident as a loss of reactivity to PLP (A-C), intense inflammatory infiltrates of CD68 ${ }^{+}$ cells (D-F), and an accumulation of APP in transected axons and spheroids as a sign of neurodegeneration (G-I). A detail of the spatial relationship between CHI3L1+ astrocytes and APP+ spheroids is shown as a subset in H; APP: red, GFAP: white, CHI3L1: green, DAPI: blue. CHI3L1 expression was less diffuse and more restricted to the expanding border of the lesions (arrows), and most cells were morphologically identified as astrocytes (see details in J-L). Scale bar: $100 \mu \mathrm{m}(\mathrm{A}-\mathrm{L}), 20 \mu \mathrm{m}$ (details J-L); $10 \mu \mathrm{m}$ (detail in H). APP = amyloid precursor protein; CHI3L1 = chitinase 3-like 1; GFAP = glial fibrillary acidic protein; PLP = myelin proteolipid protein; PMS = progressive MS; SEL = slow-expanding lesion; $\mathrm{WM}=$ white matter.

studied its correlation with sCHI3L1 levels and its value as a potential surrogate marker for low-grade ongoing inflammation. Serum CHI3L1 levels tended to be higher in patients with PMS than in patients with RRMS (31.9 ng/mL [25-40.1] and 28.63 $\mathrm{ng} / \mathrm{mL}$ [22.5-37.6], respectively; $p=0.062$, and they were significantly higher in patients with PPMS $[38.2 \mathrm{ng} / \mathrm{mL}$, 26.7-49.8]; $p=0.014)$. However, the $\mathrm{CCHI} 3 \mathrm{~L} 1$ values were not correlated with the $\mathrm{CHI} 3 \mathrm{~L}_{1}{ }^{\mathrm{CSF}}$ values $(r=0.150 ; p=0.162)$, and they were not associated with disease activity $(p=0.1)$, Gd+ lesions $(p=0.397)$, or EDSS at the time of LP $(p=0.188)$.

\section{Discussion}

In this study, we show that $\mathrm{CHI} 3 \mathrm{~L} 1$ and $\mathrm{NfL}$ are released to the CSF in the context of acute inflammation in all the demyelinating diseases analyzed: MS, NMO, and ADEM. $\mathrm{CHI} 3 \mathrm{~L} 1^{\mathrm{CSF}}$ values only remained elevated outside the periods of relapse in patients with MS and, in particular, in those with a progressive disease. From the pathologic studies, it appears that elevated NfL values are correlated with neuroaxonal damage, evident through the presence of $\mathrm{APP}+$ axons, and CHI3L1 in MS might be a marker for more global tissue injury, induced not only in macrophages/microglia as a probable reaction to adaptive inflammation but also, in astrocytes, possibly as a stress response to low-grade chronic inflammation and ongoing neurodegeneration.

Although in all inflammatory demyelinating diseases CHI3L1 was expressed strongly in active lesions, only NfL CSF levels corresponded to disease activity. Thus, we infer from our data that the CSF concentration of a biomarker may not only be proportional to the extent of its local production in the focal lesion but also it may depend on other factors. An important feature that may influence the concentration of a CNS protein in the CSF is its ability to diffuse through the narrow 

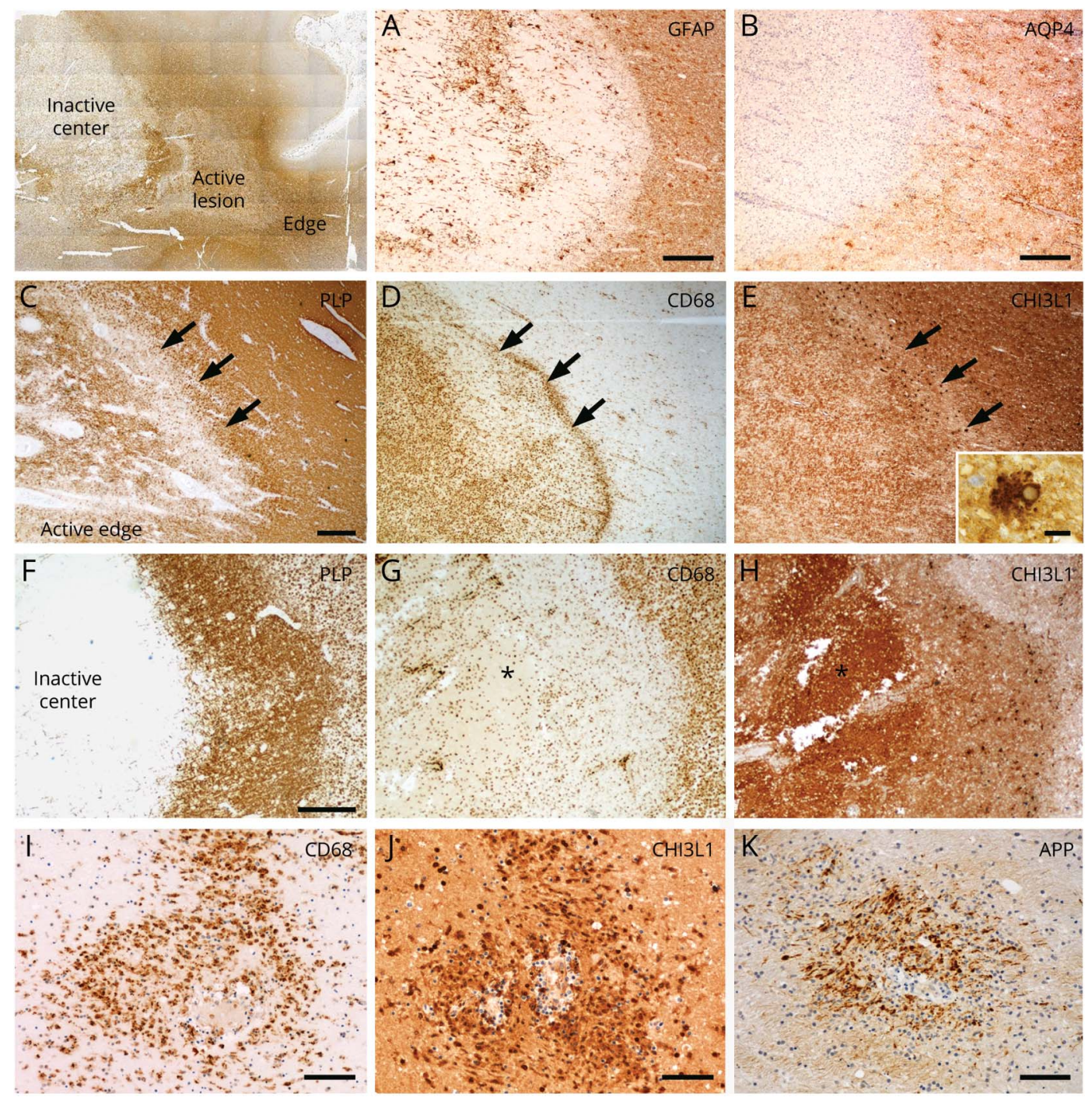

Light microscopy micrographs of a case of NMO and of ADEM. NMO (A-H). Active lesions in NMO were devoid of GFAP (A) and AQP4 (B), reflecting astrocyte damage. Loss of PLP reactivity at the active border of the lesion is related to active demyelination (C). The active edge showed CD68 $(D)$ and CHI3L1 (E) infiltrates. All CHI3L1+ astrocytes had a disrupted morphology as a result of a process referred to as clasmatodendrosis (detail in E). At the inactive center of the lesion, residual demyelination could be observed in the absence of inflammatory cells (F-G), and CHI3L1+ extracellular debris was seen (asterisk in $\mathrm{H}$ ). Scale bar: $250 \mu \mathrm{m}(\mathrm{A}, \mathrm{B}) ; 100 \mu \mathrm{m}(\mathrm{C}-\mathrm{J}) ; 10 \mu \mathrm{m}$ (detail in E and K). ADEM = acute disseminated encephalomyelitis; AQP4 = aquaporin type 4; CHI3L1 = chitinase 3-like 1; GFAP = glial fibrillary acid protein; NMO = neuromyelitis optica; PLP = myelin proteolipid protein.

extracellular space of the brain and spinal cord. We only saw elevated $\mathrm{CHI} 3 \mathrm{~L} 1^{\mathrm{CSF}}$ in patients with intense radiologic activity and predominant periventricular or cortical/juxtacortical lesions, i.e., with active inflammation. The compartmentalization of the brain and crosstalk between the CSF brain and CSF pial barriers could explain this phenomenon, as suggested previously. ${ }^{30}$ The diffusion rate of a protein in the brain extracellular space is determined by its molecular size and molecular charge. Although the molecular weights of NfL and CHI3L1 are similar, there is an important difference in their molecular charge. $\mathrm{CHI} 3 \mathrm{~L} 1$ is a strongly cationic protein ${ }^{31}$ that may bind to the anionic surface of astrocytes within the brain extracellular space, restricting its diffusion in the CNS like other cationic proteins. ${ }^{32}$ Likewise, and unlike NfL, the $\mathrm{sCHI} 3 \mathrm{~L} 1^{12}$ levels are not correlated with those in the CSF, which may again be due to more restricted diffusion through the brain extracellular space and across the BBB.

In $\mathrm{NMO}$ and $\mathrm{ADEM}, \mathrm{CHI} 3 \mathrm{~L} 1$ is expressed and released into the CSF in association with clinical bouts. ${ }^{14,15}$ Although in these diseases CHI3L1 was present in activated macrophages and microglia at active lesions, the extremely high levels of $\mathrm{CHI} 3 \mathrm{~L}^{\mathrm{CSF}}$ detected in the case of NMO may be related to the release of CHI3L1 from damaged astrocytes. Indeed, CHI3L1 was expressed in degenerating astrocytes at the active lesion edge, and it also formed aggregates in the extracellular space around the inactive lesion center. A similar pattern has been described for other astrocyte proteins, such 
as GFAP and S-100b, which are also released into the extracellular space by degenerating astrocytes ${ }^{33}$ and that accumulate to very high levels in the CSF during the acute phase of the disease. ${ }^{34}$ Clinical ADEM is characterized by diffuse brain inflammation at several locations and numerous $\mathrm{Gd}+$ lesions. This widespread inflammation might explain the increase in CHI $3 \mathrm{~L}^{\mathrm{CSF}}$ during a clinical attack. In active ADEM lesions, CHI3L1 appears to be expressed by macrophages/microglia but not by astrocytes. The absence of CHI3L1-expressing astrocytes in the patient with ADEM could, at least in part, be due to a later induction of $\mathrm{CHI} 3 \mathrm{~L} 1$ expression by astrocytes as the patient died 2 days after onset. Alternatively, it could have been due to a distinct pathogenic mechanism of lesion production mediated by other immune cell types.

Outside of relapse, median $\mathrm{CHI} 3 \mathrm{~L}_{1}{ }^{\mathrm{CSF}}$ levels were higher in patients with PMS than in patients with RRMS, and sCHI3L1 levels were also higher in patients with PMS, as seen previously. ${ }^{35}$ These discrepancies between RRMS and PMS may be due to differences in BBB permeability and/or the location of lesions, suggesting a different pattern of release that may be related to the lesion location or to the diffuse changes representative of the progressive disease.

The relationship between $\mathrm{CHI} 3 \mathrm{~L}^{\mathrm{CSF}}$ and active neuroinflammation, and the elevation of $\mathrm{CHI} 3 \mathrm{~L}^{\mathrm{CSF}}$ in PMS, implies a possible relationship between this biomarker and the progression of disability. The pathologic changes in patients with PMS indicate that CHI3L1 is expressed by astrocytes at the edge of chronic active lesions and that it is not correlated with lymphocytic infiltrates in the NAWM or in meningeal follicles in the vicinity of lesions. Hence, CHI3L1 in PMS might be linked to the innate immunity associated with low-grade inflammation. In fact, intrathecal B-cell accumulation, a reflection of adaptive immunity, was not correlated with $\mathrm{CHI} 3 \mathrm{~L} 1{ }^{\mathrm{CSF}}$ levels. ${ }^{36}$ Whether CHI3L1 expression fulfills a protective or pathogenic role in disease is still unclear. Although CHI3L1 expression implies a worse prognosis in several cancers and chronic inflammatory processes outside the nervous system, while there is also evidence of an anti-inflammatory role for CHI3L1 ${ }^{37}$ In support of the benefits that CHI3L1 may provide, demyelination and neuronal injury were exacerbated in a mouse experimental autoimmune encephalomyelitis model of MS lacking the CHI3L1 gene. ${ }^{38}$ In fact, the CHI3L1 knockout mice displayed extensive astrogliosis and were in a continuous proinflammatory state, suggesting that they underwent immune deregulation in the absence of the protein. ${ }^{39}$ In contrast, within the CNS, a pathogenic role for $\mathrm{CHI} 3 \mathrm{~L} 1$ in perpetuating inflammation or inflicting neuronal damage has been proposed. The CHI3L1 protein induced cytotoxicity in cultured neurons in vitro through a mechanism that is as yet unknown. ${ }^{40}$ Moreover, CHI3L1 ${ }^{\text {CSF }}$ levels increase in neurodegenerative diseases like Alzheimer disease as patients deteriorate, ${ }^{41-43}$ and high levels of this protein in amyotrophic lateral sclerosis imply a more accelerated disease course. ${ }^{44}$ We showed previously that CHI3L1 was the only independent factor associated with a 1-point EDSS progression and the possibility of receiving a diagnosis of progressive disease in patients with RRMS. ${ }^{3}$ It was also recently reported that astrocytes might have a neurotoxic and gliotoxic effect in acute and chronic MS lesions. ${ }^{45}$ Indeed, APP staining was spatially and temporally related to astrocytic CHI3L1 in active MS lesions, including chronic cortical lesions. Thus, the hypothesis that CHI3L1+ astrocytes might play a direct role in MS neurodegeneration is feasible. In fact, another astrocytic protein, the GFAP, has been proposed as a reliable biomarker of progressive damage in MS both in serum and CSF. ${ }^{46}$ The difference between these biomarkers lies in the fact that GFAP is a structural panastrocytic marker, whereas CHI3L1 expression is restricted to reactive astrocytes and microglia/macrophages, such as those seen in active inflammatory lesions, and that it might therefore provide additional pathogenic information.

Ongoing neurodegeneration does not occur in demyelinating diseases like NMO and ADEM, and indeed, we found that both entities had low $\mathrm{CHI} 3 \mathrm{L1}^{\mathrm{CSF}}$ levels during remission. Axonal damage related to astrocytes expressing CHI3L1 could explain the absence of progressive injury when these astrocytes suffer necrosis. Inactive lesions in NMO lack CHI3L1+ astrocytes because these cells had died due to disease-specific mechanisms. In the case of ADEM, CHI3L1 astrocytes might not be induced or present in the acute phase, although we lack an autopsic case in remission to confirm its absence.

Our study has some limitations. The assessment of CHI3L1 in CSF was cross-sectional, and the RRMS population with severe clinical conditions in the clinical study might be underrepresented as there were only 6 patients with EDSS score $>5$ (3.7\%). Nevertheless, all cases were accompanied by complete clinical, radiologic, and biochemical data. The pathologic samples of patients with RRMS were cases of aggressive disease or AMS, and thus, these are cases of extreme inflammation, however, an extensive clinical sample with well-characterized histologic MS lesions was analyzed. Only single cases of NMO and ADEM were available for the pathologic study.

In summary, both $\mathrm{NfL}$ and $\mathrm{CHI} 3 \mathrm{~L} 1$ are released into the CSF during acute inflammation in the demyelinating diseases studied, yet in MS, the elevation of CHI3L1 might also be linked to the progressive form of the disease. This is paralleled by pathologic evidence of low-grade nonlymphocytic inflammation by CHI3L1+ astrocytes in chronic lesions that are associated with active neurodegeneration. It would be interesting to perform a spatialtemporal assessment of $\mathrm{CHI} 3 \mathrm{~L} 1$ expression to elucidate whether it is an early or late event in the inflammatory process that triggers or maintains disease. Indeed, further prospective studies might help to strengthen the link between CHI3L1, disease progression, and neurodegeneration.

\section{Study Funding}

This study was supported by the ISCIII (PI17/01544 and $\mathrm{RD} 16 / 0015 / 0015)$ and cofinanced by the European Development Regional Fund. S. Gil-Perotín received a Rio 
Hortega fellowship from the ISCIII (CM12/00014) and from IISLAFE (post-residency program, 2019) and L. Cubas Núñez a fellowship from the ONCE (Spanish National Organization for the Blind-Talent Opportunity program).

\section{Disclosure}

L. Cubas-Núñez reports no disclosures. S. Gil-Perotín has received compensation for serving on scientific advisory boards or speaking honoraria from Biogen Idec and Sanofi-Aventis, outside the submitted work. J. Castillo-Villalba, V. López, L. SolísTarazona, R. Gasqué-Rubio, S. Carratalá-Boscá, and C. AlcaláVicente report no disclosures. F. Pérez-Miralles was part of the steering committee of the UPPMS study and has received compensation for serving on scientific advisory boards or speaking honoraria from Almirall, Biogen Idec, Genzyme, MerkSerono, Mylan, Novartis, Roche, Sanofi-Aventis, and Teva, outside the submitted work. H. Lassmann reports no disclosures. B. Casanova has received compensation for serving on scientific advisory boards or speaking honoraria from Biogen Idec, MerkSerono, Mylan, Novartis, Roche, and Sanofi-Aventis, outside the submitted work. Go to Neurology.org/NN for full disclosures.

\section{Publication History}

Received by Neurology: Neuroimmunology \& Neuroinflammation June 29, 2020. Accepted in final form December 21, 2020.

\section{Appendix Authors}

\begin{tabular}{|c|c|c|}
\hline Name & Location & Contribution \\
\hline $\begin{array}{l}\text { Laura Cubas } \\
\text { Núñez, PhD }\end{array}$ & $\begin{array}{l}\text { Neuroimmunology Unit, } \\
\text { Polytechnic and University } \\
\text { Hospital La Fe, Valencia, } \\
\text { Spain }\end{array}$ & $\begin{array}{l}\text { Performed the } \\
\text { immunohistochemistry } \\
\text { and obtained the optical } \\
\text { densitometry data and ran } \\
\text { the statistical analyses on } \\
\text { the data; revised the } \\
\text { manuscript for intellectual } \\
\text { content }\end{array}$ \\
\hline
\end{tabular}

\begin{tabular}{ll}
\hline Sara Gil- & Neuroimmunology Unit, \\
Perotín, MD, & Polytechnic and University \\
PhD & Hospital La Fe, Valencia, \\
& Spain
\end{tabular}
Spain

Designed the study and analyzed the data, collected and analyzed the clinical data, ran the statistical analyses on these data, supervised the results, wrote the manuscript, and revised the final version

\begin{tabular}{lll}
\hline $\begin{array}{l}\text { Jéssica } \\
\text { Castillo- } \\
\text { Villalba, BSc }\end{array}$ & $\begin{array}{l}\text { Neuroimmunology Unit, } \\
\text { Polytechnic and University } \\
\text { Hospital La Fe, Valencia, } \\
\text { Spain }\end{array}$ & $\begin{array}{l}\text { Helped in performing } \\
\text { biomarker measurements } \\
\text { and revised the } \\
\text { manuscript }\end{array}$ \\
\hline $\begin{array}{l}\text { Verónica } \\
\text { López, BSc }\end{array}$ & $\begin{array}{l}\text { Neuroimmunology Unit, } \\
\text { Polytechnic and University } \\
\text { Hospital La Fe, Valencia, } \\
\text { Spain }\end{array}$ & $\begin{array}{l}\text { Performed the cell } \\
\text { counting, helped design } \\
\text { the figures, and revised } \\
\text { the manuscript }\end{array}$ \\
\hline Luis Solís- & $\begin{array}{l}\text { Neurology Department, } \\
\text { University Hospital Dr } \\
\text { Tarazona, MD }\end{array}$ & $\begin{array}{l}\text { Helped to collect } \\
\text { radiologic and clinical data } \\
\text { and revised the } \\
\text { manuscript }\end{array}$ \\
& &
\end{tabular}

\section{Appendix (continued)}

\begin{tabular}{|c|c|c|}
\hline Name & Location & Contribution \\
\hline $\begin{array}{l}\text { Raquel } \\
\text { Gasqué- } \\
\text { Rubio, BSc }\end{array}$ & $\begin{array}{l}\text { Neuroimmunology Unit, } \\
\text { Polytechnic and University } \\
\text { Hospital La Fe, Valencia, } \\
\text { Spain }\end{array}$ & $\begin{array}{l}\text { Helped in performing } \\
\text { biomarker measurements } \\
\text { and revised the } \\
\text { manuscript }\end{array}$ \\
\hline $\begin{array}{l}\text { Sara } \\
\text { Carratalá- } \\
\text { Boscá, MA }\end{array}$ & $\begin{array}{l}\text { Neuroimmunology Unit, } \\
\text { Polytechnic and University } \\
\text { Hospital La Fe, Valencia, } \\
\text { Spain }\end{array}$ & $\begin{array}{l}\text { Helped to collect } \\
\text { radiologic clinical data and } \\
\text { revised the manuscript }\end{array}$ \\
\hline $\begin{array}{l}\text { Carmen } \\
\text { Alcalá- } \\
\text { Vicente, MD, } \\
\text { PhD }\end{array}$ & $\begin{array}{l}\text { Neuroimmunology Unit, } \\
\text { Polytechnic and University } \\
\text { Hospital La Fe, Valencia, } \\
\text { Spain }\end{array}$ & $\begin{array}{l}\text { Attending physician of } \\
\text { patients included in the } \\
\text { study, helped to register } \\
\text { the clinical data, and } \\
\text { revised the manuscript }\end{array}$ \\
\hline $\begin{array}{l}\text { Francisco } \\
\text { Pérez- } \\
\text { Miralles, MD, } \\
\text { PhD }\end{array}$ & $\begin{array}{l}\text { Neuroimmunology Unit, } \\
\text { Polytechnic and University } \\
\text { Hospital La Fe, Valencia, } \\
\text { Spain }\end{array}$ & $\begin{array}{l}\text { Attending physician of } \\
\text { patients included in the } \\
\text { study, helped to register } \\
\text { the clinical data, and } \\
\text { revised the manuscript }\end{array}$ \\
\hline $\begin{array}{l}\text { Hans } \\
\text { Lassmann, } \\
\text { MD, PhD }\end{array}$ & $\begin{array}{l}\text { Department of } \\
\text { Neuroimmunology, } \\
\text { Center for Brain Research, } \\
\text { Vienna, Austria }\end{array}$ & $\begin{array}{l}\text { Helped to design the } \\
\text { pathologic data collection, } \\
\text { ceded brain samples and } \\
\text { the optical densitometry } \\
\text { plug-in to analyze the } \\
\text { images, and assisted with } \\
\text { the interpretation of } \\
\text { histologic data and writing } \\
\text { of the manuscript }\end{array}$ \\
\hline $\begin{array}{l}\text { Bonaventura } \\
\text { Casanova, } \\
\text { MD, PhD }\end{array}$ & $\begin{array}{l}\text { Neuroimmunology Unit, } \\
\text { Polytechnic and University } \\
\text { Hospital La Fe, Valencia, } \\
\text { Spain }\end{array}$ & $\begin{array}{l}\text { Head of the } \\
\text { Neuroimmunology } \\
\text { laboratory and attending } \\
\text { physician of the patients } \\
\text { included in the study, } \\
\text { helped to register the } \\
\text { clinical data, study design, } \\
\text { and revised the } \\
\text { manuscript }\end{array}$ \\
\hline
\end{tabular}

\section{References}

1. Lassmann H. Multiple sclerosis pathology. Cold Spring Harb Perspect Med 2018;8 a028936.

2. Bjartmar C, Wujek JR, Trapp BD. Axonal loss in the pathology of MS: consequences for understanding the progressive phase of the disease. J Neurol Sci 2003;206: 165-171.

3. Gil-Perotin S, Castillo-Villalba J, Cubas-Nuñez L, et al. Combined cerebrospinal fluid neurofilament light chain protein and chitinase-3 like-1 levels in defining disease course and prognosis in multiple sclerosis. Front Neurol 2019;10:1008.

4. Lee CG, Da Silva CA, Dela Cruz CS, et al. Role of chitin and chitinase/chitinase-like proteins in inflammation, tissue remodeling, and injury. Annu Rev Physiol 2011;73. 479-501.

5. Bonneh-Barkay D, Wang G, Starkey A, Hamilton RL, Wiley CA. In vivo CHI3L1 (YKL-40) expression in astrocytes in acute and chronic neurological diseases. J Neuroinflammation 2010;7:34.

6. Canto E, Tintore M, Villar LM, et al. Chitinase 3-like 1: prognostic biomarker in clinically isolated syndromes. Brain 2015;138:918-931.

7. Bonneh-Barkay D, Bissel SJ, Kofler J, Starkey A, Wang G, Wiley CA. Astrocyte and macrophage regulation of YKL-40 expression and cellular response in neuroinflammation. Brain Pathol 2012;22:530-546.

8. Llorens $\mathrm{F}$, Thune $\mathrm{K}$, Tahir W, et al. YKL-40 in the brain and cerebrospinal fluid of neurodegenerative dementias. Mol Neurodegener 2017;12:83.

9. Rehli M, Niller H-H, Ammon C, et al. Transcriptional regulation of CHI3L1, a marker gene for late stages of macrophage differentiation. J Biol Chem 2003;278: 44058-44067.

10. Mane-Martinez MA, Olsson B, Bau L, et al. Glial and neuronal markers in cerebrospinal fluid in different types of multiple sclerosis. J Neuroimmunol 2016;299: $112-117$.

11. Sellebjerg F, Bornsen L, Ammitzboll C, et al. Defining active progressive multiple sclerosis. Mult Scler 2017;23:1727-1735. 
12. Disanto G, Barro C, Benkert P, et al. Serum neurofilament Light: a biomarker of neuronal damage in multiple sclerosis. Ann Neurol 2017;81:857-870.

13. Kuhle J, Nourbakhsh B, Grant D, et al. Serum neurofilament is associated with progression of brain atrophy and disability in early MS. Neurology 2017;88:826-831.

14. Correale J, Fiol M. Chitinase effects on immune cell response in neuromyelitis optica and multiple sclerosis. Mult Scler 2011;17:521-531.

15. Boesen MS, Jensen PEH, Magyari M, et al. Increased cerebrospinal fluid chitinase 3-like 1 and neurofilament light chain in pediatric acquired demyelinating syndromes. Mult Scler Relat Disord 2018;24:175-183.

16. Collongues N, Marignier R, Jacob A, et al. Characterization of neuromyelitis optica and neuromyelitis optica spectrum disorder patients with a late onset. Mult Scler 2014;20:1086-1094.

17. Kawachi I, Lassmann H. Neurodegeneration in multiple sclerosis and neuromyelitis optica. J Neurol Neurosurg Psychiatry 2017;88:137-145.

18. Thompson AJ, Banwell BL, Barkhof F, et al. Diagnosis of multiple sclerosis: 2017 revisions of the McDonald criteria. Lancet Neurol 2018;17:162-173.

19. Lublin FD, Reingold SC, Cohen JA, et al. Defining the clinical course of multiple sclerosis: the 2013 revisions. Neurology 2014;83:278-286.

20. Wingerchuk DM, Banwell B, Bennett JL, et al. International consensus diagnostic criteria for neuromyelitis optica spectrum disorders. Neurology 2015;85:177-189.

21. Krupp LB, Tardieu M, Amato MP, et al. International Pediatric Multiple Sclerosis Study Group criteria for pediatric multiple sclerosis and immune-mediated central nervous system demyelinating disorders: revisions to the 2007 definitions. Mult Scler 2013;19:1261-1267.

22. Kurtzke JF. Rating neurologic impairment in multiple sclerosis: an expanded disability status scale (EDSS). Neurology 1983;33:1444-1452.

23. Marburg O. Die sogenannte akute multiple Sklerose. Jahrb Psychiatr 1906;27:211-312.

24. Teunissen CE, Petzold A, Bennett JL, et al. A consensus protocol for the standardization of cerebrospinal fluid collection and biobanking. Neurology 2009;73:1914-1922.

25. Lucchinetti C, Bruck W, Parisi J, Scheithauer B, Rodriguez M, Lassmann H. Heterogeneity of multiple sclerosis lesions: implications for the pathogenesis of demyelination. Ann Neurol 2000;47:707-717.

26. Bruck W, Porada P, Poser S, et al. Monocyte/macrophage differentiation in early multiple sclerosis lesions. Ann Neurol 1995;38:788-796.

27. Frischer JM, Weigand SD, Guo Y, et al. Clinical and pathological insights into the dynamic nature of the white matter multiple sclerosis plaque. Ann Neurol 2015;78:710-721.

28. Lassmann H. Review: the architecture of inflammatory demyelinating lesions: implications for studies on pathogenesis. Neuropathol Appl Neurobiol 2011;37:698-710.

29. Zrzavy T, Hametner S, Wimmer I, Butovsky O, Weiner HL, Lassmann H. Loss of "homeostatic" microglia and patterns of their activation in active multiple sclerosis. Brain 2017;140:1900-1913.

30. Burman J, Raininko R, Blennow K, Zetterberg H, Axelsson M, Malmestrom C. YKL40 is a CSF biomarker of intrathecal inflammation in secondary progressive multiple sclerosis. J Neuroimmunol 2016;292:52-57.
31. Iershov A, Odynets K, Kornelyuk A, Kavsan V. Homology modeling of 3D structure of human chitinase-like protein CHI3L2. Cent Eur J Biol 2010;5:407-420.

32. Vass K, Lassmann H, Wisniewski HM, Iqbal K. Ultracytochemical distribution of myelin basic protein after injection into the cerebrospinal fluid. Evidence for transport through the blood-brain barrier and binding to the luminal surface of cerebral veins. J Neurol Sci 1984;63:423-433.

33. Misu T, Höftberger R, Fujihara K, et al. Presence of six different lesion types suggests diverse mechanisms of tissue injury in neuromyelitis optica. Acta Neuropathol 2013; 125:815-827.

34. Takano R, Misu T, Takahashi T, Izumiyama M, Fujihara K, Itoyama Y. A prominent elevation of glial fibrillary acidic protein in the cerebrospinal fluid during relapse in neuromyelitis optica. Tohoku J Exp Med 2008;215:55-59.

35. Canto E, Reverter F, Morcillo-Suarez C, et al. Chitinase 3-like 1 plasma levels are increased in patients with progressive forms of multiple sclerosis. Mult Scler 2012;18: 983-990.

36. Engel S, Friedrich M, Muthuraman M, et al. Intrathecal B-cell accumulation and axonal damage distinguish MRI-based benign from aggressive onset in MS. Neurol Neuroimmunol Neuroinflammation 2019;6:e595.

37. Im JH, Yeo IJ, Park PH, et al. Deletion of Chitinase-3-like 1 accelerates stroke development through enhancement of neuroinflammation by STAT6-dependent M2 microglial inactivation in Chitinase-3-like 1 knockout mice. Exp Neurol 2020;323:113082.

38. Bonneh-Barkay D, Wang G, Laframboise WA, Wiley CA, Bissel SJ. Exacerbation of experimental autoimmune encephalomyelitis in the absence of breast regression protein 39/chitinase 3-like 1. J Neuropathol Exp Neurol 2012;71:948-958.

39. Wiley CA, Bissel SJ, Murdoch GH. Role of CHI3L1 in neuroinflammation. Clin Immunol 2015:354.

40. Matute-Blanch C, Calvo-Barreiro L, Carballo-Carbajal I, et al. Chitinase 3-like 1 is neurotoxic in primary cultured neurons. Sci Rep 2020;10:7118.

41. Baldacci F, Lista S, Cavedo E, Bonuccelli U, Hampel H. Diagnostic function of the neuroinflammatory biomarker YKL-40 in Alzheimer's disease and other neurodegenerative diseases. Expert Rev Proteomics 2017;14:285-299.

42. Craig-Schapiro R, Perrin RJ, Roe CM, et al. YKL-40: a novel prognostic fluid biomarker for preclinical Alzheimer's disease. Biol Psychiatry 2010;68:903-912.

43. Muszynski P, Groblewska M, Kulczynska-Przybik A, Kulakowska A, Mroczko B. YKL40 as a potential biomarker and a possible target in therapeutic strategies of $\mathrm{Alz}$ heimer's disease. Curr Neuropharmacol 2017;15:906-917.

44. Andres-Benito P, Dominguez R, Colomina MJ, Llorens F, Povedano M, Ferrer I. YKL40 in sporadic amyotrophic lateral sclerosis: cerebrospinal fluid levels as a prognosis marker of disease progression. Aging (Albany NY) 2018;10:2367-2382.

45. Liddelow SA, Guttenplan KA, Clarke LE, et al. Neurotoxic reactive astrocytes are induced by activated microglia. Nature 2017;541:481-487.

46. Abdelhak A, Hottenrott T, Morenas-Rodríguez E, et al. Glial activation markers in CSF and serum from patients with primary progressive multiple sclerosis: potential of serum GFAP as disease severity marker? Front Neurol 2019;10:280. 


\section{Neurology \\ Neuroimmunology \& Neuroinflammation}

Potential Role of CHI3L1+ Astrocytes in Progression in MS

Laura Cubas-Núñez, Sara Gil-Perotín, Jéssica Castillo-Villalba, et al.

Neurol Neuroimmunol Neuroinflamm 2021;8;

DOI 10.1212/NXI.0000000000000972

This information is current as of March 3, 2021

Neurol Neuroimmunol Neuroinflamm is an official journal of the American Academy of Neurology.

Published since April 2014, it is an open-access, online-only, continuous publication journal. Copyright

Copyright $\odot 2021$ The Author(s). Published by Wolters Kluwer Health, Inc. on behalf of the American

Academy of Neurology.. All rights reserved. Online ISSN: 2332-7812.

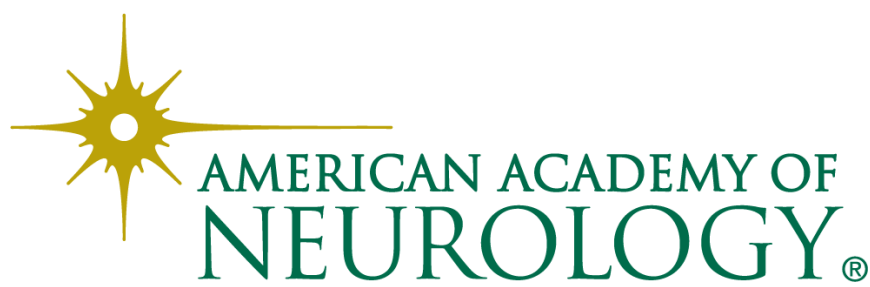




\section{Updated Information \& Services}

References

Subspecialty Collections

Permissions \& Licensing

Reprints including high resolution figures, can be found at:

http://nn.neurology.org/content/8/3/e972.full.html

This article cites 45 articles, 3 of which you can access for free at: http://nn.neurology.org/content/8/3/e972.full.html\#\#ref-list-1

This article, along with others on similar topics, appears in the following collection(s):

Acute disseminated encephalomyelitis

http://nn.neurology.org//cgi/collection/acute_disseminated_encephalo myelitis

All Demyelinating disease (CNS)

http://nn.neurology.org//cgi/collection/all_demyelinating_disease_cns All Immunology

http://nn.neurology.org//cgi/collection/all_immunology

Devic's syndrome

http://nn.neurology.org//cgi/collection/devics_syndrome

Multiple sclerosis

http://nn.neurology.org//cgi/collection/multiple_sclerosis

Information about reproducing this article in parts (figures,tables) or in its entirety can be found online at:

http://nn.neurology.org/misc/about.xhtml\#permissions

Information about ordering reprints can be found online:

http://nn.neurology.org/misc/addir.xhtml\#reprintsus

Neurol Neuroimmunol Neuroinflamm is an official journal of the American Academy of Neurology.

Published since April 2014, it is an open-access, online-only, continuous publication journal. Copyright

Copyright $\odot 2021$ The Author(s). Published by Wolters Kluwer Health, Inc. on behalf of the American

Academy of Neurology.. All rights reserved. Online ISSN: 2332-7812.

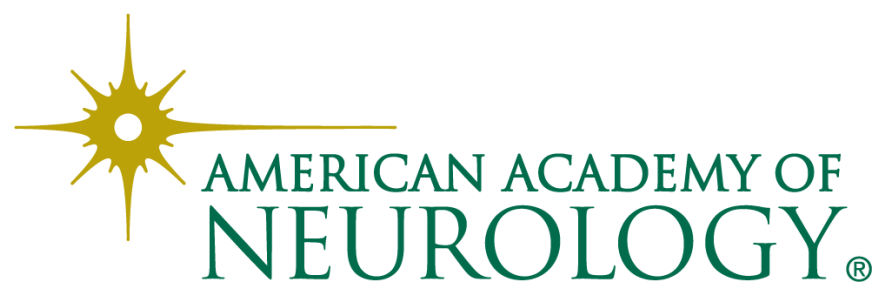

